\title{
Measurement of Earmuffs Attenuation at High Audible Frequencies
}

\author{
Emil KOZŁOWSKI, Rafał MŁYŃSKI \\ Central Institute for Labour Protection - National Research Institute \\ Czerniakowska 16, 00-701 Warszawa, Poland; e-mail: emkoz@ciop.pl \\ (received March 11, 2016; accepted February 13, 2017)
}

\begin{abstract}
Standardised measurements of sound attenuation of hearing protectors are performed in the frequency range from $125 \mathrm{~Hz}$ to $8 \mathrm{kHz}$. However, noise present at many workplaces contains significant components at higher audible frequency. Therefore, the knowledge about noise attenuation with earmuffs in the audible frequency range above $8 \mathrm{kHz}$ is also necessary for proper hearing protection. The aim of this study was to obtain values of the noise attenuation with 27 commonly-used earmuffs models in the $1 / 3$ octave bands of 10, 12.5 and $16 \mathrm{kHz}$. The measurements were conducted with a real ear at threshold (REAT) method with participation of subjects. The study showed that attenuation of earmuffs ranged from 24.7 to $42.8 \mathrm{~dB}$, depending on model of earmuffs and frequency band. Furthermore, the measurements were performed with the use of acoustic test fixture which is designed especially for testing hearing protectors. Results obtained with the use of acoustic test fixture indicated that this measurement method can lead to values close to attenuation measured with participation of subjects. On the other hand, values obtained with the use of acoustic test fixture may differ average up to $14 \mathrm{~dB}$ from REAT method.
\end{abstract}

Keywords: hearing protectors; earmuffs; sound attenuation; high frequencies.

\section{Introduction}

Noise in the audible frequency range above $8 \mathrm{kHz}$ is generated for instance in places where high-speed cutting machines are operated (non-ferrous metalworking), while using hand tools such as angle grinders or testing jet aircraft engines, and also where compressed air valves are used (Smagowska, 2013). Such noise can cause dizziness, headaches, loss of balance, nausea, and tinnitus. It can also cause fatigue and irritability (SMagowsKa, PAWlaczYK-Łuszczyóska, 2013).

In many cases with noise in the high audible frequency range, there are no other means of protecting hearing than hearing protectors (earmuffs or earplugs). The role of hearing protectors was also acknowledged in the case of impulse noise (MŁYŃski et al., 2014) or noise produced during shotblasting (ŻERA, MŁYŃsKI, 2004). For the normally considered frequency range, i.e. from $125 \mathrm{~Hz}$ to $8 \mathrm{kHz}$, hearing protectors are selected on the basis of results of measurements of noise parameters in a workplace, using data on sound attenuation given in the user manual supplied with a hearing protector (EN 458:2016). Sound attenuation measurements are taken by determining the difference be- tween the hearing thresholds with the occluded ear and with the open ear. This subjective method for determining the attenuation of hearing protectors is known as a REAT method (Real Ear At Threshold) (EN 24869-1:1992). Properties of hearing protectors can be also examined using the MIRE method (Microphone In Real Ear) where a miniature microphone inserted into a person's ear is used (EN ISO 119041:2002). Moreover, noise reduction provided by hearing protectors can also be assessed by using devices reflecting a person's head, referred to as acoustic test fixtures. The use of acoustic test fixtures leads to an objective method resulting in insertion loss values being obtained (EN ISO 4869-3:2007, LENZUNI et al., 2012).

However, where exposure to noise with audible frequencies above $8 \mathrm{kHz}$ needs to be considered, there are no systematic figures on the basis of which it can be concluded that a specific hearing protector adequately protects the hearing of an employee. Only very few studies reveal information about testing the attenuation efficiency of hearing protectors for noise in the audible frequency range above $8 \mathrm{kHz}$. One of the relevant studies includes tests which are limited only to a few selected models of hearing protectors of which hear- 
ing properties are determined by an objective method (Crabtree, Behar, 2000). The results presented in another study do not give any figures for the reduction of ultrasonic noise provided by hearing protectors (PAWLACZYK-ŁUSZCZYŃSKa et al., 2013). However, they indicate that following eight-hour exposure to noise generated by ultrasonic welders, no temporary deterioration of hearing was reported. Moreover, the used hearing protectors provided effective protection against this noise.

The results of this study complement what is known about acoustic properties of the commonly used earmuffs in the audible frequency range above $8 \mathrm{kHz}$ (for the 10, 12.5 and $16 \mathrm{kHz}$ frequency bands). Obtained data allows to ensure that the hearing protection against that noise will lead to a reduction in the sound pressure level to values safe for the hearing of an employee.

\section{Materials and methods}

\subsection{Earmuffs}

Tests were carried out on 27 models of the commonly used earmuffs from five manufacturers: $3 \mathrm{M}$ Peltor, Howard Leight, MSA, Hellberg, and JSP. Twentyfour models of earmuffs were available in a version with a head band, whereas three other models were attached to an industrial safety helmet (3M Peltor G3000 Solaris). A list of all tested earmuffs is presented in Table 1 that allows to identify earmuffs for selection purposes.

\subsection{REAT method}

Measurements of sound attenuation in $1 / 3$ octave bands in the audible frequency range above $8 \mathrm{kHz}$ were carried out using the REAT method, normally applied

Table 1. Results of the sound attenuation measurements of earmuffs in the audible frequency range above $8 \mathrm{kHz}$.

\begin{tabular}{|c|c|c|c|c|}
\hline \multicolumn{2}{|c|}{ Earmuffs } & \multicolumn{3}{|c|}{$1 / 3$ octave-band center frequency } \\
\hline \multirow[b]{2}{*}{ Manufacturer } & \multirow[b]{2}{*}{ Model } & $10 \mathrm{kHz}$ & $12.5 \mathrm{kHz}$ & $16 \mathrm{kHz}$ \\
\hline & & \multicolumn{3}{|c|}{$\begin{array}{c}\text { Sound attenuation }[\mathrm{dB}] \\
\text { Mean } \pm \text { standard deviation }\end{array}$} \\
\hline \multirow{9}{*}{ 3M Peltor } & H510A & $31.1 \pm 4.0$ & $34.8 \pm 4.2$ & $39.7 \pm 3.3$ \\
\hline & $\mathrm{H} 520 \mathrm{~A}$ & $30.3 \pm 4.2$ & $34.0 \pm 5.1$ & $42.6 \pm 3.9$ \\
\hline & $\mathrm{H} 540 \mathrm{~A}$ & $30.2 \pm 4.2$ & $35.2 \pm 4.3$ & $40.9 \pm 2.9$ \\
\hline & $\mathrm{X} 1 \mathrm{~A}$ & $28.6 \pm 2.4$ & $34.1 \pm 4.6$ & $40.2 \pm 3.7$ \\
\hline & $\mathrm{X} 2 \mathrm{~A}$ & $31.0 \pm 4.0$ & $34.0 \pm 4.8$ & $39.0 \pm 5.0$ \\
\hline & $\mathrm{X} 3 \mathrm{~A}$ & $30.3 \pm 4.1$ & $35.2 \pm 4.4$ & $40.4 \pm 4.4$ \\
\hline & $\mathrm{X} 4 \mathrm{~A}$ & $33.1 \pm 1.9$ & $36.7 \pm 4.7$ & $42.8 \pm 3.4$ \\
\hline & $\mathrm{X} 5 \mathrm{~A}$ & $32.0 \pm 2.9$ & $35.5 \pm 4.5$ & $42.2 \pm 2.7$ \\
\hline & H520P3 & $32.0 \pm 3.1$ & $36.4 \pm 4.9$ & $41.9 \pm 5.1$ \\
\hline \multirow{7}{*}{ Howard Leight } & Leightning L1 & $26.9 \pm 2.7$ & $30.2 \pm 4.2$ & $34.6 \pm 2.4$ \\
\hline & Leightning L2 & $25.3 \pm 3.9$ & $29.9 \pm 5.3$ & $36.2 \pm 3.0$ \\
\hline & Leightning L3 & $27.0 \pm 3.7$ & $30.9 \pm 4.3$ & $35.4 \pm 4.6$ \\
\hline & Viking V1 & $24.7 \pm 3.2$ & $29.3 \pm 4.7$ & $33.9 \pm 3.1$ \\
\hline & Viking V3 & $26.1 \pm 4.3$ & $29.2 \pm 5.1$ & $34.3 \pm 2.7$ \\
\hline & Thunder T3 & $30.3 \pm 4.6$ & $32.5 \pm 6.6$ & $39.1 \pm 4.2$ \\
\hline & Leightning L1H & $26.4 \pm 3.4$ & $30.3 \pm 5.1$ & $35.0 \pm 3.8$ \\
\hline \multirow{3}{*}{ MSA } & XLS & $31.3 \pm 3.6$ & $35.6 \pm 6.0$ & $40.9 \pm 4.0$ \\
\hline & EXC & $31.6 \pm 2.8$ & $34.8 \pm 5.1$ & $41.4 \pm 3.7$ \\
\hline & HPE & $32.1 \pm 2.3$ & $34.8 \pm 4.9$ & $41.0 \pm 3.3$ \\
\hline \multirow{4}{*}{ Hellberg } & Secure $1 \mathrm{H}$ & $25.7 \pm 2.1$ & $29.3 \pm 4.1$ & $34.0 \pm 5.2$ \\
\hline & Secure $2 \mathrm{H}$ & $25.1 \pm 4.3$ & $27.5 \pm 4.7$ & $34.0 \pm 5.9$ \\
\hline & Secure $3 \mathrm{H}$ & $27.7 \pm 4.4$ & $30.1 \pm 5.7$ & $35.3 \pm 6.7$ \\
\hline & Secure $2 \mathrm{C}$ & $25.0 \pm 3.2$ & $29.5 \pm 3.4$ & $36.3 \pm 3.6$ \\
\hline \multirow{4}{*}{ JSP } & Classic gp & $27.5 \pm 3.1$ & $31.5 \pm 5.3$ & $39.0 \pm 4.4$ \\
\hline & Economuff & $25.0 \pm 4.7$ & $27.7 \pm 4.5$ & $39.2 \pm 2.2$ \\
\hline & J Muff & $25.2 \pm 3.2$ & $25.9 \pm 3.9$ & $33.7 \pm 4.4$ \\
\hline & Monaco & $30.2 \pm 3.2$ & $34.1 \pm 5.4$ & $38.7 \pm 5.3$ \\
\hline
\end{tabular}


in the frequency range of up to $8 \mathrm{kHz}$. A pink noise filtered in $1 / 3$ octave bands with the centre frequencies of $10,12.5$, and $16 \mathrm{kHz}$ was used as a test signal. The test signal was generated using the Norsonic NOR838 system controlled by a PC, a test signal shaping set (Yamaha YDG 2030 graphic equalizer, JBL DSC 260 limiter, Crown Macro-tech 2400 power amplifier), and three JBL SR4722A loudspeaker sets (located around a person every $120^{\circ}$ ). Due to the measurements of the hearing threshold, the tests were carried out in a room providing a low background noise level. Ten subjects were selected for the tests. The criterion for selection of a subject was the condition that the person could hear the test signal and correctly respond to this signal in $1 / 3$ octave bands with the centre frequencies of 10 , 12.5 , and $16 \mathrm{kHz}$. Each subject had to respond to both the quietest and loudest test signals. The tests carried out with participants consisted in measuring the hearing thresholds of each subject in two situations, i.e. with the occluded ear (the loudest test signals) and with the open ear (the quietest test signals). The final test result was the sound attenuation value obtained (the difference between the results achieved in both of the above-mentioned situations). A photograph of a person during the measurement of the threshold of hearing is presented in Fig. 1.

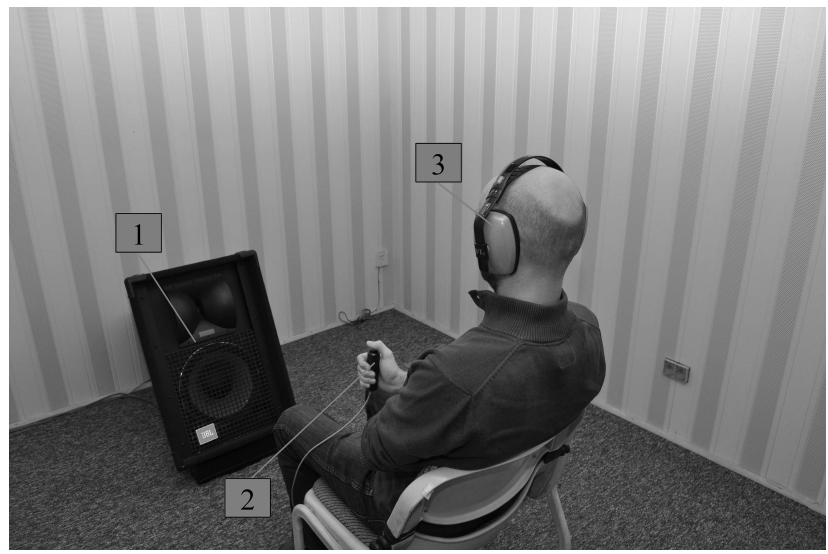

Fig. 1. Subject in the measurement of sound attenuation provided by earmuffs: 1 - one of the three loudspeaker sets, 2 - response button for the test subject, 3 - tested earmuffs.

\subsection{Acoustic test fixture}

Usually acoustic test fixtures are used to control product quality. Moreover, the acoustic test fixtures are used to replace the participation of subjects in testing acoustic properties of hearing protectors. One of the advantages of using acoustic test fixtures is possibility to get results faster than using the REAT method (with subjects). The most advanced device for this purpose is G.R.A.S. $45 \mathrm{CB}$ acoustic test fixture complies with standard ANSI/ASA S12.42-2010. This acoustic test fixture is close, with a high level of accuracy, to the sound attenuation values measured with subjects in the frequency range of up to $8 \mathrm{kHz}$ (BERGER et al., 2012). This test fixture, due to the solutions applied, is not a device intended only to control product quality but it is also a specialized device for testing acoustic properties of hearing protectors. These solutions are representation of anatomical shapes of the head and ear, presence of ear simulators shaping the test fixture frequency characteristics similar to the ones observed in humans and presence of the heating system used for heating up to a temperature of $37^{\circ}$.

The purpose of the tests carried out in this work was to assess the suitability of the use of acoustic test fixture to achieve an approximation of the results obtained by the REAT method for the frequencies: 10, 12.5 , and $16 \mathrm{kHz}$.

The tests carried out using the acoustic test fixture covered the same $1 / 3$ octave bands with the centre frequencies: $10,12.5$, and $16 \mathrm{kHz}$, as in the case of the measurements taken using the REAT method. The equipment making the test signals was identical to the equipment used during the measurements made using the REAT method (measurements of sound attenuation with subjects). Unlike the subjective method, the objective method was based on the measurements of the sound pressure level (linear frequency weighting) with two G.R.A.S. 40BP microphones (left and right ear) of the G.R.A.S. 45CB acoustic test fixture. The measurements of the sound pressure level were carried out in two situations: when the test fixture was not provided with earmuffs and when the test fixture was provided with earmuffs. The final test result was the "insertion loss", i.e. the difference between the results achieved in these two above-mentioned situations. In this situation, when the result is the difference between two identical situations except the presence of hearing protector on the acoustic test fixture, the frequency responses of used microphones were not critical. Nevertheless, it should be noted that the frequency response

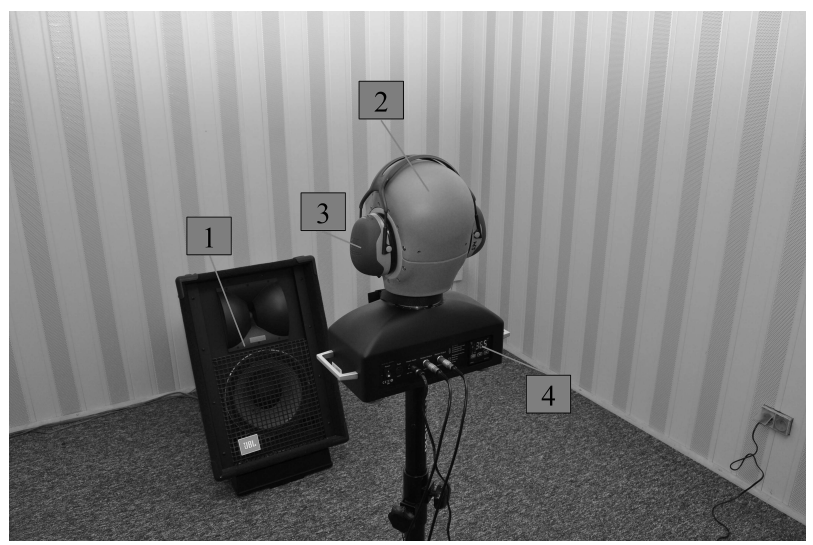

Fig. 2. Acoustic test fixture used in the measurement of the insertion loss of the earmuffs: 1 - one of the three loudspeaker sets, 2 - acoustic test fixture, 3 - tested earmuffs, 4 - heating module display indicating the temperature. 
of G.R.A.S. 40BP microphone is flat $( \pm 1 \mathrm{~dB})$ up to $25 \mathrm{kHz}$. The test of each earmuff was repeated 3 times; therefore, the final result was achieved on the basis of 6 measurements (3 measurements per each earmuff cup).

The presented tests were carried out using the measurement unit of the Brüel \& Kjær PULSE system and the G.R.A.S. 12AA module, powering the microphones and amplifying the measurement signal, in the data acquisition line.

The photograph presenting the acoustic test fixture during the sound pressure level measurement under one of the earmuffs is featured in Fig. 2.

\section{Results}

\subsection{Sound attenuation}

The test results for the sound attenuation determined with the participation of 10 subjects, in the audible frequency range above $8 \mathrm{kHz}$, in the case of 27 earmuffs, are included in Table 1 . In the case of each tested earmuffs the mean value and standard deviation of sound attenuation were calculated. The given values of standard deviation reflect the discrepancies among subjects.

When analyzing the data included in Table 1, it can be noticed that the mean values of the measured attenuation fall within the range from 24.7 to $33.1 \mathrm{~dB}$ for the $10 \mathrm{kHz}$ frequency band, from 25.9 to $36.7 \mathrm{~dB}$ for the $12.5 \mathrm{kHz}$ frequency band, and from 33.7 to $42.8 \mathrm{~dB}$ for the $16 \mathrm{kHz}$ frequency band. The highest attenuation values were observed in the case of the $3 \mathrm{M}$ Peltor X4A earmuffs in each of the three analysed frequency bands. The lowest sound attenuation values were measured for the Howard Leight Viking V1 earmuffs in the case of the $10 \mathrm{kHz}$ band, and for the JSP J Muff earmuffs in the case of the 12.5 and $16 \mathrm{kHz}$ bands. The standard deviation of the measured sound attenuation was values within the range from 1.9 to $6.7 \mathrm{~dB}$. These values are similar to the values obtained in sound attenuation measurements conducted for typical frequency range (up to $8 \mathrm{kHz}$ ).

The obtained sound attenuation data in the case of 27 tested earmuffs were compared with the values of the catalogue $H$ parameter of these earmuffs. The $H$ parameter is one of the four single value parameters $(H, M, L$ and SNR) use to describe the attenuation of earmuffs (in the range from $125 \mathrm{~Hz}$ to $8 \mathrm{kHz}$ ) and they are included in the information for the user (EN ISO 4869-2:1995). These parameters are calculated based on eight reference noise spectra (with different sound pressure levels in particular frequency bands) and the individual sound attenuation values of the hearing protector. The $H, M$ and $L$ parameters represent attenuation respectively in a high, medium and low frequency range. The SNR is single number rating including equally all frequency bands. The $H$ parameter, despite the fact that it refers to frequencies not higher than $8 \mathrm{kHz}$, characterises the hearing protectors in the range closest to the range of the completed tests, from mentioned parameters. Therefore, the $H$ parameter was taken into account in further presentation of the results.

Diagrams of the measured sound attenuation as a function of the $H$ parameter of the earmuffs are presented in Fig. $3(10 \mathrm{kHz}$ frequency band), Fig. 4 (12.5 kHz frequency band), and Fig. 5 (16 kHz frequency band). In the above-mentioned figures, the data are broken down by particular earmuff manufacturers.

On the basis of the data included in Figs. 3-5, it can be stated that the sound attenuation in the audible frequency range above $8 \mathrm{kHz}$ has increasingly high values with increasing frequency. The highest values were observed for the earmuffs manufactured by $3 \mathrm{M}$ Peltor and MSA. When comparing the results for the earmuffs manufactured by 3M Peltor and Howard Leight having

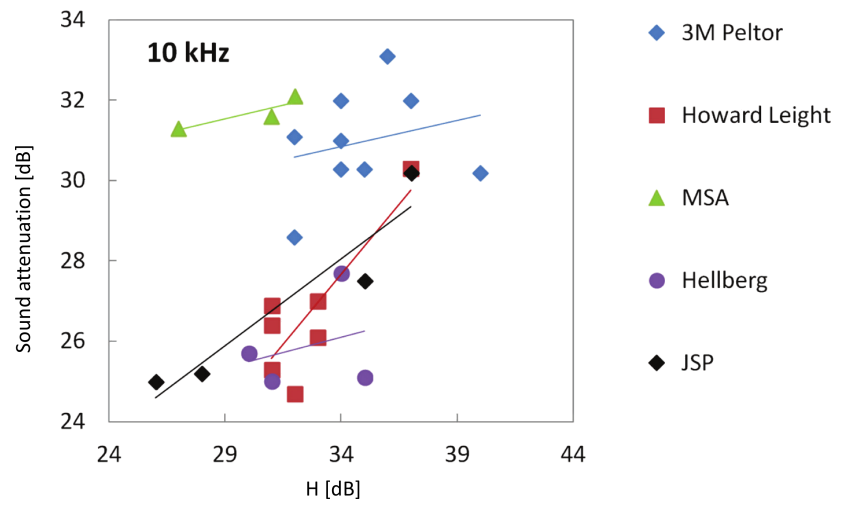

Fig. 3. The mean value of sound attenuation in the $1 / 3$ octave bands with the $10 \mathrm{kHz}$ centre frequency as a function of the catalogue $H$ parameters (determined in the range of up to $8 \mathrm{kHz}$ ) for the earmuffs broken down by manufacturers. Trend lines indicated within earmuffs of a given manufacturer are drawn with solid lines.

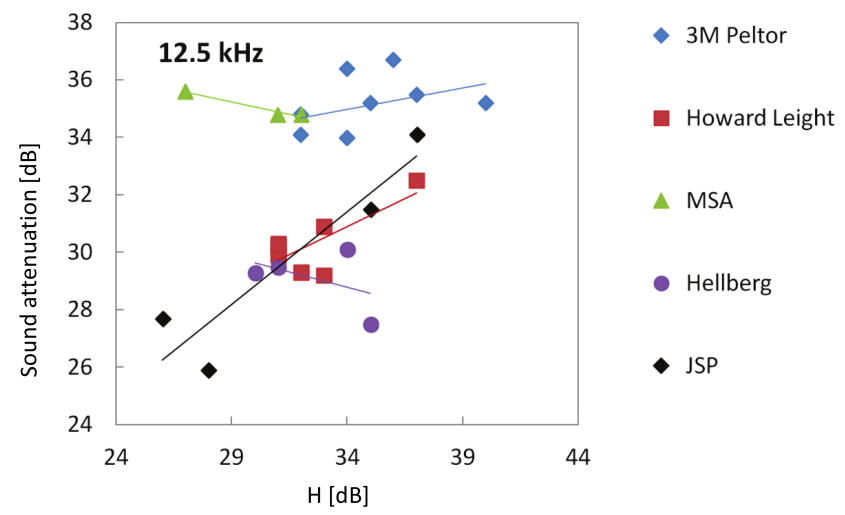

Fig. 4. The mean value of sound attenuation in the $1 / 3$ octave bands with the $12.5 \mathrm{kHz}$ centre frequency as a function of the catalogue $H$ parameters (determined in the range of up to $8 \mathrm{kHz}$ ) for the earmuffs broken down by manufacturers. Trend lines indicated within earmuffs of a given manufacturer are drawn with solid lines. 


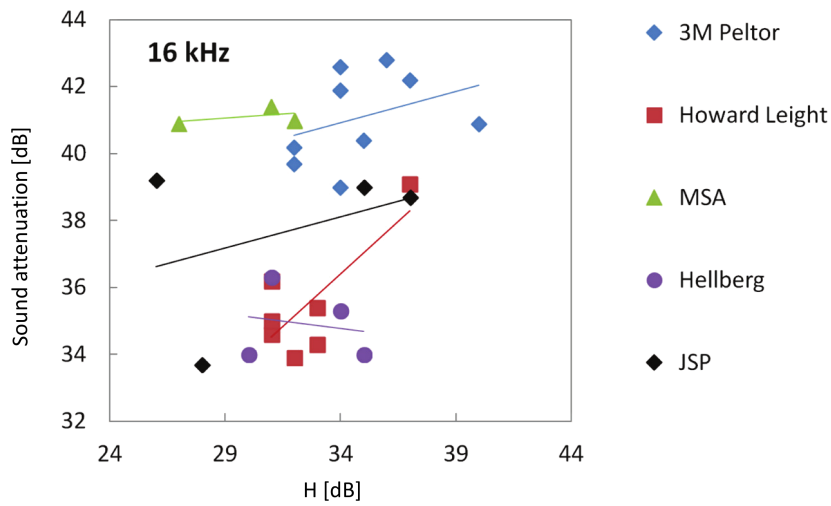

Fig. 5. The mean value of sound attenuation in the $1 / 3$ octave bands with the $16 \mathrm{kHz}$ centre frequency as a function of the catalogue $H$ parameters (determined in the range of up to $8 \mathrm{kHz}$ ) for the earmuffs broken down by manufacturers. Trend lines indicated within earmuffs of a given manufacturer are drawn with solid lines.

similar $H$ parameter values, it can be noticed that the sound attenuation for the 3M Peltor earmuffs is significantly higher (by approximately $5-8 \mathrm{~dB}$ ) values than for the Howard Leight earmuffs. The same also applies when comparing the results for the earmuffs manufactured by 3M Peltor and Hellberg (approximately 5-6 dB higher attenuation than for the 3M Peltor earmuffs). The difference between the sound attenuation values of the earmuffs of a given manufacturer can be not higher than $0.8 \mathrm{~dB}$ (for the MSA earmuffs), and on the other hand, it can be as high as $8.2 \mathrm{~dB}$ (the JSP earmuffs).

The presented results show that increasing $H$ parameter (determined for the standard frequency bands up to $8 \mathrm{kHz}$ ) does not always lead to increased sound attenuation value of particular earmuff models in the frequency bands above $8 \mathrm{kHz}$. However, the sound attenuation trend as a function of the $H$ parameter value grows in the majority of analysed cases. The MSA earmuffs $(10 \mathrm{kHz}$ frequency band) and the Hellberg earmuffs (10 and $12.5 \mathrm{kHz}$ frequency bands), for which the trend line slope coefficient is negative, are an exception to this rule.

\subsection{Insertion loss}

Figure 6 presents the difference between the results of the insertion loss measured using the acoustic test fixture and the sound attenuation measured using the REAT method with subjects, in the audible frequency range above $8 \mathrm{kHz}$, in the case of 27 earmuffs included in the tests.

The results presented in Fig. 6 show that the insertion loss values measured using the acoustic test fixture are close to the results obtained with subjects in a restricted manner. In the case of the $10 \mathrm{kHz}$ frequency band, for each of 27 earmuffs considered in the tests, the results obtained using the test fixture are never

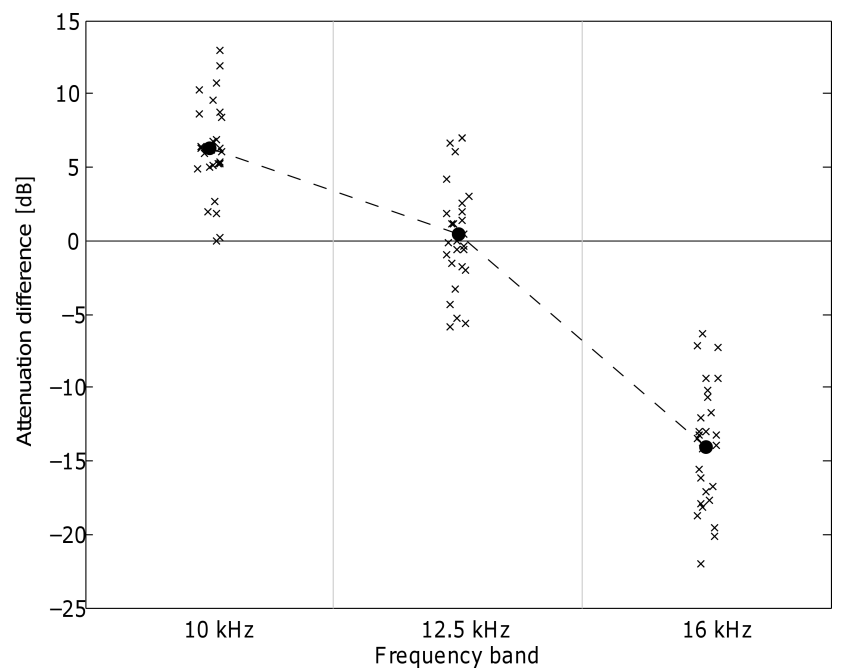

Fig. 6. The difference between the insertion loss measured using the acoustic test fixture and the sound attenuation measured with subjects, in the case of 27 earmuffs; $(\times)-$ individual data, dots $(\bullet)$ - average values of differences.

lower than the results obtained with subjects. In one situation, there was no difference between the sound attenuation and the insertion loss, and for the other 26 earmuffs, there was a case of attenuation overestimation by the test fixture. The highest attenuation overestimation amounted to $12.9 \mathrm{~dB}$ and, on average, it amounted to $6.3 \mathrm{~dB}$. In the case of the $12.5 \mathrm{kHz}$ frequency band, the test fixture overestimates and underestimates the attenuation measured with subjects. The highest underestimation was $5.9 \mathrm{~dB}$, whereas the highest overestimation was $7 \mathrm{~dB}$. The average discrepancy was $0.4 \mathrm{~dB}$. However, in the case of the $16 \mathrm{kHz}$ frequency band, the opposite situation than in the case of the $10 \mathrm{kHz}$ frequency band occurs, i.e. the insertion loss measured using the test fixture for each of the 27 earmuffs was lower than the sound attenuation measured with subjects. The discrepancy was between $6.4 \mathrm{~dB}$ and $22 \mathrm{~dB}$. The average attenuation underestimation by the test fixture was $14 \mathrm{~dB}$. As it mentioned earlier, G.R.A.S. 45CB acoustic test fixture is close, with a high level of accuracy, to the sound attenuation values measured with subjects in the frequency range of up to $8 \mathrm{kHz}$ (BERGER et al., 2012). In this study, in the considered frequency range above $8 \mathrm{kHz}$, higher discrepancies between the results measured by the test fixture and with subjects were found. A possible cause of greater discrepancies is that the design of the test fixture and the materials used for its design do not represent, with sufficient accuracy, the physical features of persons in the frequency range above $8 \mathrm{kHz}$.

\section{Summary}

The results of the presented tests provided data on the noise reduction offered by the commonly used 
27 models of earmuffs, in the audible frequency range above $8 \mathrm{kHz}$, which have not been achievable until now. The data complement what is known about the acoustic properties of the commonly used earmuffs. Such data can allow to correct selection of hearing protectors according to the noise generated in the workplace. The selection will ensure that the used earmuffs will reduce the sound pressure level (for the centre frequencies in the range from $10 \mathrm{kHz}$ to $16 \mathrm{kHz}$ ) to below the values hazardous to the hearing.

The results of the carried out tests indicated significant differentiation of the sound attenuation values in the audible frequency range above $8 \mathrm{kHz}$ between particular earmuffs. From among the commonly used 27 models of earmuffs, the attenuation values measured for them change within the range from $24.7 \mathrm{~dB}$ for the $10 \mathrm{kHz}$ band to $42.8 \mathrm{~dB}$ for the $16 \mathrm{kHz}$ band.

The tests indicated that there is no uniform relation between the sound attenuation in the audible frequency range above $8 \mathrm{kHz}$ and the catalogue $H$ parameter of earmuffs. Therefore, it is not possible to predict in a straightforward way the noise attenuation in the frequency range above $8 \mathrm{kHz}$, e.g. using the sound attenuation data for the normally considered frequency range (up to $8 \mathrm{kHz}$ ). The data characterising the attenuation of earmuffs for the frequencies of $10 \mathrm{kHz}$, $12.5 \mathrm{kHz}$, and $16 \mathrm{kHz}$ should be therefore measured.

The results of the carried out tests indicate that using the acoustic test fixture to characterise the properties of earmuffs beyond the standard frequency range (in the audible frequency range above $8 \mathrm{kHz}$ ) means limited accuracy when determining the noise attenuation. Using the acoustic test fixture can lead both to the values close to the sound attenuation measured with subjects, as well as cause overestimation (on average, by $6.3 \mathrm{~dB}$ ) or underestimation (on average, by $14 \mathrm{~dB}$ ) of this attenuation.

\section{Acknowledgments}

This paper has been based on the results of a research task carried out within the scope of the third stage of the National Programme "Improvement of safety and working conditions" partly supported in 2014-2016 - within the scope of state services - by the Ministry of Labour and Social Policy. The Central Institute for Labour Protection - National Research Institute is the Programme's main co-ordinator.

\section{References}

1. ANSI/ASA S12.42-2010, Methods for the Measurement of Insertion Loss of Hearing Protection Devices in Continuous or Impulsive Noise Using Microphonein-Real-Ear or Acoustic Test Fixture Procedures.

2. Berger E.H., Kieper R.W., Stergar M.E. (2012), Performance of New Acoustical Test Fixtures Complying with ANSI S12.42-2010, with Particular Attention to the Specification of Self Insertion Loss, Proceedings of the INTER-NOISE 2012, August 19-22, New York, USA.

3. Crabtree R.B., Behar A. (2000), Measurement of hearing protector insertion loss at ultrasonic frequencies, Applied Acoustics, 59, 3, 287-299.

4. EN ISO 11904-1:2002, Acoustics - Determination of sound immission from sound sources placed close to the ear - Part 1: Technique using a microphone in a real ear (MIRE technique).

5. EN ISO 4869-2:1995, Acoustics - Hearing protectors Part 2: Estimation of effective A-weighted sound pressure levels when hearing protectors are worn.

6. EN ISO 4869-3:2007, Acoustics - Hearing protectors Part 3: Measurement of insertion loss of ear-muff type protectors using an acoustic test fixture.

7. EN 24869-1:1992, Acoustics - Hearing protectors. Sound attenuation of hearing protectors - Subjective method of measurement.

8. EN 458:2016, Hearing protectors. Recommendations for selection, use, care and maintenance, Guidance document.

9. Lenzuni P., Sangiorgi T., Cerini L. (2012), Attenuation of peak sound pressure levels of shooting noise by hearing protective earmuffs, Noise Health, 14, 58, 91-99.

10. MŁyński R., KozŁowski E., Adamczyk J. (2014), Assessment of impulse noise hazard and the use of hearing protection devices in workplaces where forging hammers are used, Archives of Acoustics, 39, 1, 73-79.

11. Pawlaczyk-Łuszczyńska M., Zaborowski K., DuDAREWICZ A. (2013), Evaluation of efficiency of personal hearing protective devices in case of exposure to ultrasonic noise. Proceedings of the 16th International Conference on Noise Control 2013, May 26-29, Ryn, Poland.

12. Smagowska B. (2013), Ultrasonic noise sources in a work environment, Archives of Acoustics, 38, 2, 169176.

13. Smagowska B., Pawlaczyk-Łuszczyńska M. (2013), Effects of ultrasonic noise on the human body - a bibliographic review, International Journal of Occupational Safety and Ergonomics (JOSE), 19, 2, 195-202.

14. ŻERA J., MŁYŃski R. (2004), Attenuation of outside noise by shotblasting helmets, Archives of Acoustics, 29, 2, 347-358. 